\title{
Benefits of infant massage for mothers with postnatal depression
}

\author{
Vivette Glover, Katsuno Onozawa and Alison Hodgkinson \\ Queen Charlotte's and Chelsea Hospital
}

Semin Neonatol 2002; 7: 495500

Key words: massage, infant, postnatal depression

Infant massage by the mother has been popular in many cultures, especially India, and is growing in popularity in the West. Mothers with postnatal depression often have problems interacting with their infants. A small controlled study has shown that attending a massage class can help such mothers relate better to their babies. The mechanisms by which this is achieved are not clear but may include learning to understand their babies' cues and the release of oxytocin.

Postnatal depression

Postnatal depression is a major problem, affecting about $10 \%$ of those giving birth each year, or about 70000 in the UK alone. Several studies have shown that women with postnatal depression often have problems relating to their new baby $[1,21$. They can seem indifferent, and not smile or talk to their infants as much as other mothers do; alternatively they can be over intrusive and handle their babies roughly. The babies, in turn, often behave in a distressed and abnormal fashion, either with excessive crying or by becoming passive and withdrawn [3]. The effects of this have been shown to persist until the infant is at least 18 months of age [4]. Several studies have also shown that children of women with postnatal depression tend to do less well later, both in terms of their behaviour and their intelligence [5,6]. This may well be, at least in part, because their mothers have not been able to give them the necessary stimulation and affection in the early months. Postnatal depression itself is readily treatable [7]. However, although individual directed psychotherapy has been claimed to be of help [81, so far, no simple intervention has been shown to improve the early mother baby interaction.

\section{Potential benefits of massage}

Attending a massage class had the potential to be of benefit for early mother infant interaction as such classes specifically encourage mothers to look at and understand their babies, as well as interacting with them in a pleasurable manner. It has previously been shown that massage by a nurse is beneficial for such babies in a variety of ways [9]. Benefits of massage have been claimed to include improved neuropsychological development [10], better sleeping patterns [9,11,121 and weight gain [12]. Massaged babies have also been found to have improved learning and recovery from habituation [131 and relief with constipation and symptoms of colic (Hernandez Reif personal communication). Massage and music therapy has also been shown to change the EEG patterns of depressed mothers [14].

Trial of infant massage for mothers with postnatal depression Our recent study determined whether attending an infant massage class could help mothers with postnatal depression learn to interact better with their babies [151. The primary intended outcome was an improvement in the mother baby relation ship. A second possible beneficial outcome was an improvement in the mothers' depression.

First time mothers who gave birth to single healthy babies at Queen Charlotte's and Chelsea Hospital were posted the Edinburgh Postnatal Depression Scale (EPDS) [16] at 4 weeks postpartum. This is a self rating scale which has been well validated as a screening tool for postnatal depression. All those who scored 13 or over, were asked to participate in the trial. They were assigned into either the massage or the control group, depending on the period of their recruitment. 
Baseline characteristics of the two groups were the same. Those in the massage group joined in the classes already ongoing at Queen Charlotte's. Twelve in the massage group and 13 in the control group completed the study attending 5

sessions over a period of up to 8 weeks. The infants were on average 9 weeks old at the start of the study. Nine mothers failed to complete the study, 73 in the massage group and 2 in the controls. The major reason for dropout was the inconvenient time of the massage class. There was no difference in baseline depression score or other parameters in the two groups or in those that completed and those that did not. All mothers attended a weekly directed support group session at which they were encouraged to discuss problems and offer mutual support.

The primary assessment was by video recording interaction between mother and baby [2]. The baby sits in a baby chair and the mother is asked to play with him or her for $5 \mathrm{~min}$. The recording is later scored for a number of factors, such as maternal intrusiveness and mother baby interaction. This method has been well validated by other researchers. This assessment was carried out at the first session and again at the end of the trial. The scoring of the videotapes was checked by an experienced practitioner, blind to the mother's group. In addition the mothers filled in the EPDS at their first and last sessions.

The EPDS scores showed that while the depression of control mothers who attended the support group improved over the period, the improvement of the massage group was significantly greater (Fig 1).

The primary measure was the scoring of the video film for mother baby interaction (Fig 2). This showed that the initial scores for all the mothers were low, indicating poor interaction, as expected. The scores for the mothers in the control group stayed the same for the period of the trial. However the scores for the mothers who attended the massage classes improved greatly. The difference in the change in the mother baby interaction score between the beginning and end of the trial, in the two groups, is highly statistically significant $(\mathrm{P}<0.001)$. All the specific subscales for both mother and infant showed similar patterns.

The benefit of the massage classes to the mothers and babies was very clear. Although other studies have shown that both counselling and drug treatment can improve mothers' depression, this is the first time that an improvement in mother baby interaction has been established. The study was small and only followed mothers up for the period of the trial. It needs to be repeated on a larger scale and with a longer follow up. However it does seem likely that massage classes of the type described here have a potentially very important, acceptable and safe role, in helping women who have problems in interacting with their baby. They certainly are enjoyed by the mothers.

Possible role for oxytocin

It is possible that a physiological mechanism contributes to the benefit observed. It is well established in animal models that oxytocin promotes maternal behaviour [171. It has also been shown that being massaged increased plasma oxytocin levels in healthy adult women [18], and that periods of breast massage of their mothers by newborn infants also increased the maternal oxytocin concentration [19]. Thus massage may induce oxytocin in both mother and infant and this may promote their bonding relationship. This should be an interesting area for future research.

The nature of the parent infant massage classes

In our study, massage instructors followed the philosophy of the International Association of Infant Massage (IAIM), which was founded by Vimala McClure in 1986 [20]. Teachers use dolls allowing parents to gain confidence in handling their own baby, and to understand their baby's needs through touch and the observation of cues. The classes are run by instructors all trained by IAIM, some of whom are nurses. Appointments can be made by phone or parents just 'drop in'. Classes are offered for babies under three months and from three months to crawling. Two instructors work together, one teaching the class and the other supporting booking latecomers, giving an extra towel, showing a more comfortable position for the baby, or helping a distressed mother.

Training curriculum

The instructor training curriculum is based on:

(1) Stimulation and development of all physiological systems;

(2) Relaxation, including a technique adapted by McClure from conditioned response relaxation 
and yoga;

(3) Relief, including techniques for parents to help relieve colic, pain, teething discomfort, congestion and emotional stress.

(4) Communication skills between parent and baby, to aid attachment and interaction.

Group facilitation is an important aspect, creating a space for parents to feel relaxed, free to air

feelings in discussions, encouraged to respond to their infants' cues, and confident in the growing

awareness of their child.

The massage strokes are inspired by Indian and Swedish massage traditions, reflexology and yoga.

Teaching is based on the principles of the IAIM where the Instructor is non judgmental and not

'the expert'. The class is planned to allow time for parents to concentrate on their babies without external interruptions, to learn to massage and touch with respect, and to focus on their child's nonverbal (body language) and verbal communication (crying/their voice). In a warm, safe environment, parents gain confidence in coping and interacting with their child [21]. Parents have also felt free to ask questions about the various specialities of the teachers, e.g. parent interest generated the compilation of a simple music tape and words, which has proved an excellent aid for giving confidence to sing at home as well as encouraging parents who are often self conscious, at first, in class.

By allowing the class to be baby lead, the parent begins responding to the baby's needs; and through positive experiences, the parent's selfesteem also grows. The newborn, or those born pre term, may cope with only one or two body areas being massaged or none. The baby may not wish to be undressed: or prefer to be held or allowed to lie still. Some babies indicate that they want frequent breaks for feeding, cuddling, time to cry, to calm or to sleep. Some parents are anxious about touching their tiny child: "I lost the fear of touching and handling my baby";

"It has given me confidence to physically handle my new baby, particularly in the first weeks". Through massage, the parent learns about their baby's skin by observing its texture, temperature, tone, relaxation, stimulation [22]. It boosts confidence to be able to ease a baby's colicky symptoms with an appropriate massage routine; to use touch relaxation to calm an anxious baby or to say, "I know you are frightened", or to reassure, "You are safe with me".

A mother's words: "it makes me feel good and empowered. If is terrific to be in an environment where the baby can cry without fear of criticism". "The touching creates a special bonding sensation". Massage skills perpetuate past the class; "massage especially at home makes him relaxed and content".

The older babies often enjoy longer massage. More rhymes and nursery songs can be introduced along with toys to hold, chew on or to discover. More coordination exercises and games are taught as the babies become stronger.

Fathers, carers, grandparents and siblings are welcome. Cullen et al. [231 have shown how this can benefit the father's relationship with the child. Second time mothers come to enjoy uninterrupted time with their newborn; and they often glean ideas to adapt to their toddler at home to help with toddler jealousy and their need for special attention also. "It makes me feel confident (even second time round) to hear what other mothers are going through. Helps me relax. I am able to spend an entire hour, just the two of us".

IAIM instructors begin each class by encouraging the parent to ask 'permission' and respond to their baby's state. This acknowledges that babies have a part to play in the care they are receiving, and teaches the mother to observe constantly the state her baby is in. For instance, the baby may indicate by the position of the hands or arms (e.g finger splaying, high guard or an unsynchronized punching movement with the arms) that this may not be the right moment for massage. As the parent moves to each new body area, they observe their baby and ask, "May I massage your legs (or face or tummy ... )?" By pausing and focusing, the parent takes time to notice the infant's waking and sleeping states; and to adjust their handling to be appropriate. This all helps the mother to learn to understand the infant's body language, and may foster a better mother infant interaction and attachment.

When parents/carers introduce themselves and their baby, they are often keen to contribute to a topic which the Instructor introduces such as:

'Can you describe any signs your baby gives before he cries?',

'What does your baby do if he is overwhelmed by too much stimulation?, 'Have you noticed ways that your baby calms himself ?, 'How do you know your baby is saying 'Yes' to massage?',

'What expectations did you have of how your baby would sleep?, 
'What expressions does your baby make, or imitate?'

It is an informal way of understanding infant cues and behaviour. As each week progresses, the parent becomes increasingly aware of their baby's behaviour and its meaning. They absorb a subtle understanding of their child's reactions. A parent may be anxious or excited to share experiences: they may prefer to quietly observe and learn from their baby and/or the group. They are drawn in to their baby's social world.

"The classes have helped me think about the way I react to my baby and have developed my responses".

"The babies enjoy the attention and it does appear to relax and soothe them. They really enjoy the other babies".

Importance of the group

With mothers leaving hospital soon after the birth, or feeling isolated on the intensive care ward, such a class can reassure mothers and help with leaming or coping. The Instructors may encourage a parent to seek help where needed or channel them toward an appropriate service (e.g. breastfeeding counsellor, their general practitioner or other organizations). The parents have helped compile a folder of support groups, clubs and activities in the community. They regularly contribute ideas to support other parents and invite each other to share social activities. "In the early days it was interesting and reassuring to see other babies of the same age and to know that any worries I had were shared by other mothers."

\section{Evaluations}

Evaluations are handed out after five sessions, for the Instructors to gauge what the parent feels they gain from the class and to consider any benefits for their baby. Evaluations are used to appraise and revise the service in keeping with the needs of the parents. The quotes included in this article are taken from these anonymous evaluations.

Postnatal depression

The Instructors welcomed the opportunity to have a study conducted on the possible benefits of massage for mothers with postnatal depression.

Over the years, they have observed that many mothers seemed withdrawn, nervously

overenthusiastic or over intrusive. Some mothers choose a corner, away from the direct vision of the Instructor; or regularly arrive late and busy themselves with nappy changing etc. They may find eye contact difficult to maintain when asking permission to massage. Their difficulty in responding to cues may be covered up through constant feeding and care giving. A mother may use light fingertip touch that a baby may find hypersensitive, appearing to reject massage; or she may be over intrusive and continue massaging when the baby is signalling for her to stop or rest. The mother may state, "my baby doesn't like me."

The anonymous evaluations after five sessions are honest:

"I have learnt that massaging my baby can help me to cope with difficult circumstances in a more positive frame of mind";

"At 3 months my GP thought I was at risk of post natal depression (mother had psychosis) and I found the massage classes v. helpful good social contact for me and the baby. Helpful hints about childcare. Keep them going please."

The future

The service would need to grow considerably if it were to offer classes to all new parents. However, the cost of giving a support base to new parents may be cheaper in the long term, than the cost of regular visits to the general practitioner and other support agencies. A recent study highlighted that crying and sleeping problems in the first 12 weeks, costs the National Health Service f 65 million a year in consultations with health visitors and general practitioners, enough to fund over 2000 nurses [241. If one could reduce the amount of behavioural problems in children of mothers with postnatal depression, the financial savings, as well as improvement in child mental health, may similarly be considerable. Thus there may be a considerable cost benefit if Infant Massage Instructors were routinely included as part of Parent Education in the postnatal services of maternity hospitals.

In a parent's words, "I am a doctor myself, a surgeon, and would naturally be a little bit sceptical about such things, but I am convinced it is a good use of resources 
Table 1. Mechanisms by which massage may help mother infant interaction

o relaxation of mother and baby

o increased confidence of mother

o maternal improvement in understanding baby cues

o release of oxytocin promoting bonding

Acknowledgments

The quotations are all taken from mothers who had attended the classes at Queen Charlotte's and Chelsea Hospital. The Infant Massage Instructors involved in this study were Cherry Bond, Alison Hodgkinson and Lowell Herbert.

\section{References}

I Stein A, Gath DH, Bucher J, et al. The relationship between postnatal depression and mother infant interaction. British Journal of Psychiatry 1991; 158: 4652.

2 Murray L, Fiori Cowley A, Hooper R, et al. The impact of postnatal depression on infant development and associated adversity on early mother infant interactions and later infant outcome. Child Development 1996; 67: 25122526.

3 Tronick EZ, Weinberg MK. Depressed mothers and infants: failure to form dyadic states of consciousness. In: Murray L, Cooper PJ (eds) Postpartum Depression and Child Development. London: The Guilford Press. 1997; 5481.

4 Edhborg M, Lundh W, Seimyr L, Widstrom A M. The long term impact of postnatal depressed mood on mother child interaction: a preliminary study. Journal of Reproductive and Infant Psychology 2001; 19: 6171.

5 Cogill S, Caplan H, Alexandra H, et al. Impact of postnatal depression on cognitive development of young children. BMJ 1988; 292: 11651167.

6 Sharp D, Hay DF, Pawlby S, Schumacher G, Allen H, Kumar R. The impact of postnatal depression and boy's intellectual development. Journal of Child Psychology and Psychiatry 1995; 36: 13151336.

7 Appleby L, Warner R, Whitton A, ef al. A controlled study of fluoxetine and cognitive behavioural counselling in the treatment of postnatal depression. BMJ 1997; 314: 932936. 8 Cramer B, Robert Tissot C, Stern D, et al. Outcome evaluation in brief mother infanL psychotherapy. A preliminary report. Infant Mental Health 1990; 11: 278300.

9 Field T, Grizzle N, Scafidi F, et al. Massage therapy for infants of depressed mothers. Infant Behaviour and Development 1996; 19: 107112.

10 Rice R. Neurophysiological development in premature infants following stimulation. Developmental Psychology 1997; 13: 6976.

11 Scafidi F, Field T, Schanberg S, Bauer C, Bega Lahr N, Garcia R. Effects of tactile/kinesthetic stimulation on the clinical course and sleep/wake behavior of preterm neonates. Infant Behavior and Development 1986; 9: 91105.

12 Agarwal KN, Gupta A, Pushkarna R, Bhargava SK, Faridi MMA, Prabhu MK. Effects of massage and use of oil on growth, blood flow and sleep pattern in infants. Indian Journal of Medical Research 2000; 112: 212217.

13 Cigales M, Field T, Lundy B, Cuadra A, Hart S. Massage enhances recovery from habituation in normal infants. Infant Behavior and Development 1997; 20: 2934.

14 Jones N, Field T. Right frontal EEG asymmetry is attenuated by massage and music therapy. Adolescence 1999; 34: 529534.

15 Onozawa K, Glover V, Adams D, Modi N, Kumar R. Infant massage improves mother infant interaction for mothers with postnatal depression. Journal of Affective Disorders 2001; 63: 201 207.

16 Cox JL, Holden JM, Sagovsky R. Detection of postnatal depression: development of the Edinburgh Postnatal Depression Scale. British Journal of Psychiatry 1987; 152: 799806. 17 Levy F, Kendrick KM, Goode JA, Guevara Guzman R, 24 Keverne E. Oxytocin and vasopressin release in the olfactory bulb of parturient ewes. Brain Research 1995; 16: 197206. 18 Turner RA, Altemus M, Enos T, Cooper B, McGuinness T. Preliminary research on plasma oxytocin in normal cycling women: investigating emotion asnd interpersonal distress. Psychiatry 1999; 62: 97113.

19 Malthiesen AS, Ransjo Arvidson AB, Nissen E, UvnasMoberg K. Postpartum maternal oxytocin release by newborn: effects of infant hand massage and sucking. Birth 2001; 28: 139. 
20 McClure V. Infant Massage: A Handbook for Loving Parents, 3rd Revised Edition NY: Bantam, 2000.

21 Klaus MH, Kennell JH, Klaus PH. BONDING: Building the Foundations of Secure Attachment and Independence. AddisonWesley, 1995.

22 Montagu A. Touching: The Human Significance of the Skin, 3rd Edition NY: Harper \& Row, 1986.

23 Cullen C, Field T, Escalona A, Hartshorn K. Father infant interactions are enhanced by massage therapy. Early Child Development and Care 2000; 164: 4147.

24 Morris S, St James Roberts 1, Sleep J, Gillham P. Economic evaluation of strategies for managing crying and sleeping problems. Archives of Disease in Childhood 2001; 84; 1519 